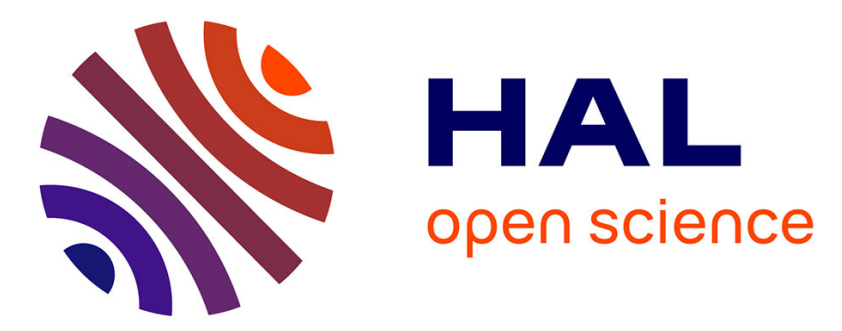

\title{
Development of testing methods for winding turn-to-turn insulation of low voltage motors fed by PWM converters
}

\author{
Veronika Bolgova, Stéphane Lefebvre, Sami Hlioui, Nidhal Boucenna, François \\ Costa, Andrey Leonov
}

\section{To cite this version:}

Veronika Bolgova, Stéphane Lefebvre, Sami Hlioui, Nidhal Boucenna, François Costa, et al.. Development of testing methods for winding turn-to-turn insulation of low voltage motors fed by PWM converters. 19th European Conference on Power Electronics and Applications (EPE'17 ECCE Europe), 2017, Warsaw, Poland. hal-01657565

\section{HAL Id: hal-01657565 \\ https://hal.science/hal-01657565}

Submitted on 6 Dec 2017

HAL is a multi-disciplinary open access archive for the deposit and dissemination of scientific research documents, whether they are published or not. The documents may come from teaching and research institutions in France or abroad, or from public or private research centers.
L'archive ouverte pluridisciplinaire HAL, est destinée au dépôt et à la diffusion de documents scientifiques de niveau recherche, publiés ou non, émanant des établissements d'enseignement et de recherche français ou étrangers, des laboratoires publics ou privés. 


\title{
Development of testing methods for winding turn-to-turn insulation of low voltage motors fed by PWM converters
}

\author{
Veronika Bolgova $^{(1,2)}$, Stéphane Lefebvre ${ }^{(1)}$, Sami Hlioui ${ }^{(1)}$, Nidhal Boucenna ${ }^{(1)}$, \\ François Costa $^{(1)}$, Andrey Leonov ${ }^{(2)}$ \\ (1) SATIE, CNRS UMR 8029, ENS PARIS-SACLAY, \\ 61 Avenue du Président Wilson 94235 \\ Cachan, France \\ Tel.: + $33(0) 147402113$ \\ (2) NATIONAL RESEARCH TOMSK POLYTECHNIC UNIVERSITY, \\ POWER ENGINEERING INSTITUTE \\ 30 Lenin Avenue 634050 \\ Tomsk, Russia \\ Tel.: +7(3822) 606333 \\ E-Mail: veronika.bolgova@satie.ens-cachan.fr \\ URL: http://satie.ens-paris-saclay.fr
}

\section{Keywords}

«Electrical machine», «Insulation», «Pulse Width Modulation (PWM)», «Silicon Carbide (SiC)», «Test bench», «Variable speed drive», «Wide bandgap devices».

\begin{abstract}
Electrical insulation materials quality and reliability play a central role in providing the electrical machines reliable operation. It is well recognized that insulating system of low voltage motor fed by converter is exposed to electrical stresses arising from repetitive square waveform of supplying voltage while additional impact of temperature, vibrations and environmental operation conditions are imposed. The implementation of wide bandgap power semiconductors as $\mathrm{SiC}$ and $\mathrm{GaN}$ in recent years allows to create very powerful converters with high switching speed. On the other hand it leads to a remarkable increasing electro-thermal constraints applied to windings' turn-to-turn insulation of motors fed by such converters. The relevance of new testing methods and test benches is well found by remarkable modern advances in semiconductors technology. Testing methods for low voltage motors winding wires insulation proposed in this paper permit to evaluate the withstand capability of insulation materials applying the high frequency modulated signals representative for traditional converters supplying ( $\mu$ s level of impulse rise/fall time), as well as the voltage waveforms with very straight adjustable $\mathrm{dV} / \mathrm{dt}$, very fast rise time and fall time (ns level of impulse rise/fall time) engendered by new semiconductor devices based on wide bandgap materials. The possibility to modify experiment parameters in wide rage for insulation endurance tests allows to obtain a rich data for further analysis.
\end{abstract}

\section{Introduction}

It is widely known from previous research that the implementation of Pulse Width Modulation (PWM) based power converters having better performances enabled by the high switching speed besides their obvious advantages leads to a drastic increase in electrical stresses in low voltage electrical machines [1-3].

Electrical machines generally constitute the final element of an energy conversion chain; they are at the interface between the power converter and the mechanical system. Therefore, they constitute a preferred route for the transmission of electromagnetic interferences in the environment and are also influenced by electrical stresses characterized by steep rising and falling pulses with very straight 
fronts (high $\mathrm{dV} / \mathrm{dt}$ ) generated by converters, reflected waves in cable line, mismatching of cable and motor winding impedance caused by high frequency component in variable frequency drives (VFD) systems. So that leads to an appearance of over-voltages at the motor terminals [3-6] that can reach the values up to the Partial Discharge Inception Voltage (PDIV).

The partial and corona discharges occur in voids and defects existing in the insulation in the delivered condition due to insulating technology, as well as in voids and localized defects appearing during the electrical machines operation. These defects can be located between the insulation surface and the stator core, in the insulation between different phases, or between winding's turns [7]. The partial discharges activity in the voids provokes the complex physico-chemical process caused by accelerated electrons and ions bombardments, gas-discharge radiation, temperature increasing, chemically active substances produced by these discharges, and increased local electrical intensity in affected areas. Partial discharges in voids give rise to the deterioration of dielectric material around these voids increasing the size of the voids and the intensity of the partial discharges [8]. As the insulation degrades, the number and magnitude of partial discharges pulses will increase, thus the insulation system is weakened due to persistent discharges and a complete failure occurs. Occurring partial discharges are at the same time both a symptom of an insulation defect presence and a degradation process that can lead to the final failure.

During the operation, electrical machines are exposed to various influencing factors such as electrical stresses, temperature, vibrations, pressure, humidity, and corrosion environment. The studies show that humidity impact on partial discharges appearance has lower significance than the pressure and the temperature ones $[6,8]$. Thus the conditions leading to insulation breakdown are the low pressure and elevated temperature. Typical situation is, for example, encountered in aeronautic applications. This observation is in good correlation with Zhurkov's thermo fluctuational approach of bonds destruction. According to this theory the breaking of chemical bonds in material occurs due to the energy of thermal fluctuations of atoms creating these bonds. Electrical, thermal and mechanical stresses decrease the potential barrier and facilitate the breaking [9].

The main means limiting the electrical stresses in motor windings insulation are to apply the filter methods, to optimize the configuration of the system "converter - cable - motor", and / or to increase the insulation resistance to high $\mathrm{dV} / \mathrm{dt}$ by using corona resistant enameled wires containing inorganic nanoparticles enhancing the dielectric strength.

To evaluate the withstand capability of the winding wire to the stresses applied to the motor powered by converter different methods are used. In the test methods described in the current standards $[10$, 11], two types of winding wires insulation, Type I and Type II, are distinguished according to their rated voltage level, and, therefore, for wires covered by Type I insulation the presence of the partial discharges is undesirable. So the objective of these tests is to qualify and to control the insulation quality by demonstrating the absence of partial discharges during the tests under the voltage threshold determined by electrical machines operating conditions. On the other hand, references [1-3, 12] have shown the possible presence of partial discharges in motors in VFD systems. Thus the methods based on the study of the partial discharges appearance designed for high voltage electrical machines and transformers have been adapted for medium and low voltage machines powered by converters since their applying has changed the constraints and therefore the dielectrics aging and degradation processes. The main objectives are to characterize partial discharges, the conditions of their appearance and the influence of their presence on the insulation [12-15], or to detect insulation defects [16] with the ultimate goal of developing insulation lifetime models depending on the applied constraints and their interaction [17].

The implementation of wide bandgap power semiconductor components ( $\mathrm{SiC}$ and $\mathrm{GaN}$ ) in several applications results in the increase of electrical stresses in electrical machines. The higher switching speeds in comparison with silicon components obtained with wide bandgap devices lead to the raise of common mode currents and $\mathrm{dV} / \mathrm{dt}[18,19]$. 
Thus testing methods must be adapted to the operating conditions taking into account the possible constraints (temperature, electrical stresses, humidity, pressure, vibrations), fetching out the most important ones, as well as the difficulties of their interaction analysis, the limit of the tests duration (the accelerated aging can be used to evaluate dielectrics endurance), and considering the available equipment. In order to evaluate the ability of enameled winding wire to withstand the typical PWM stresses applied to motors, in particular electrical and thermal stresses (thermoelectric nature of aging) as well as impregnation quality, the tests on the twisted pairs can be conducted [7, 10, and 15]. This paper therefore suggests two testing methods for insulation between adjacent turns of the windings of electrical machines fed by converters. The designed test benches make it possible to reproduce the severe stresses exposed to the windings insulation, namely, electrical and thermal, to characterize the thermoelectric aging. These simple methods allow to evaluate the withstand capability of the solid dielectrics used in electrical machines fed by voltage waves with different levels of $\mathrm{dV} / \mathrm{dt}$ and the influence of power converters on the motors windings electrical insulation robustness.

\section{Corona resistance testing method}

The suggested method allows to estimate the mean time to failure of twisted pairs made of winding wire in conditions close to the operational stresses for motors fed by converters based on silicone technology.

In accordance with [20] tested samples were the standard twisted pairs of winding wire (Fig. 1).

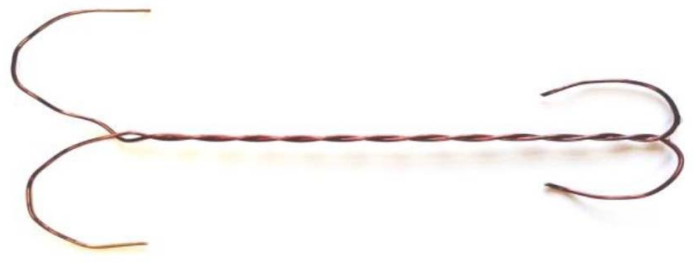

Fig. 1: Standard twisted pair of low-voltage winding

Samples were placed into a climate chamber and tests were carried out at a temperature corresponding to a relative thermal index of tested wires. The twisted pairs were exposed to high-frequency electric stresses created using specially designed equipment; the block scheme of the bench is shown in Fig. 2 .

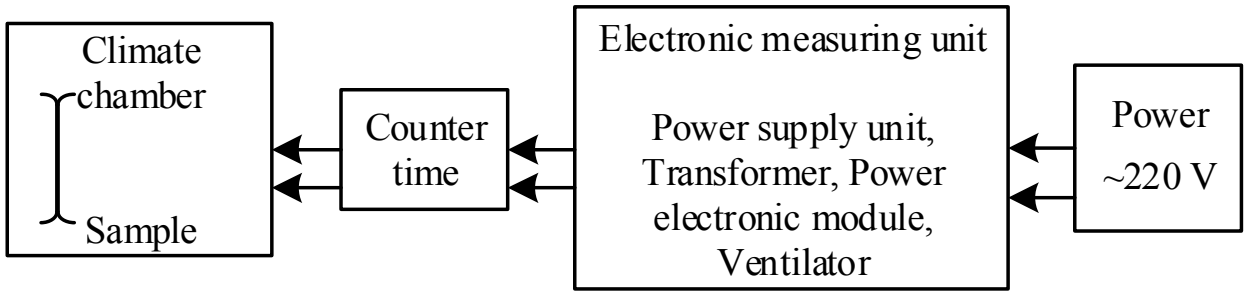

Fig. 2: Block scheme of test bench

High frequency signals modulated by designed pulse generator (Fig.3) pass via high voltage isolated bus to test twisted pairs installed in the climate chamber. The parameters of generated signals are: an alternating rectangular voltage with the amplitude equal to $1200 \mathrm{~V}$, frequency of $400 \mathrm{~Hz}$ with the quantization voltage frequency (modulation) of $5 \mathrm{kHz}$, with the rise time equal to $4 \mu \mathrm{s}$, and $\mathrm{dV} / \mathrm{dt}$ equal to $0,3 \mathrm{kV} / \mu \mathrm{s}$ [21]. Generated electrical impulses lead to appearance of corona and partial discharges across the twisted part of samples during the experiment (Fig.3). 

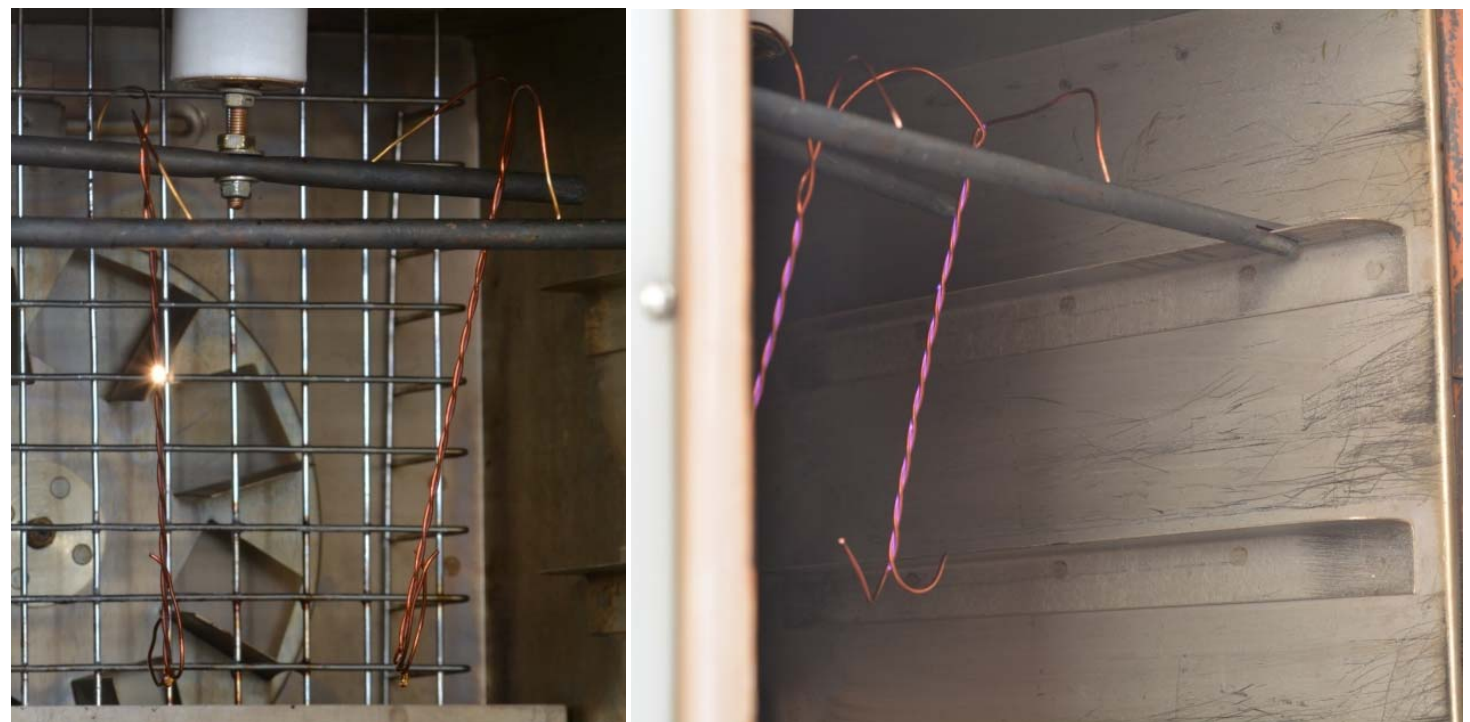

Fig. 3: Testing twisted pairs' installation and appearance of corona effect (purple light on the twists)

During the test the accelerated electro-thermal aging of twisted pairs' insulation is engendered. Partial discharges and corona occurring due to applied stresses (temperature and voltage pulses amplitude) lead to enamel insulation damage followed by breakdown. The mean time to failure was chosen as the criterion for evaluating the insulation endurance. In order to obtain a plentiful experimental data for further statistical analysis and minimize random errors for each type of studied wire no less than 30 samples were tested; with a regard to conduct tests based on design of experiments technique the number of replicates was calculated according to number and levels of investigated factors. The factorial and dispersion analysis of experimental results show the significant influence of electrical stresses on insulation aging process as well as the important role of temperature and voltage interaction.

The charts in Fig. 4 and 6 represent examples of experimental results obtained on this test bench. The different enameled copper wires of the same external diameter have been studied:

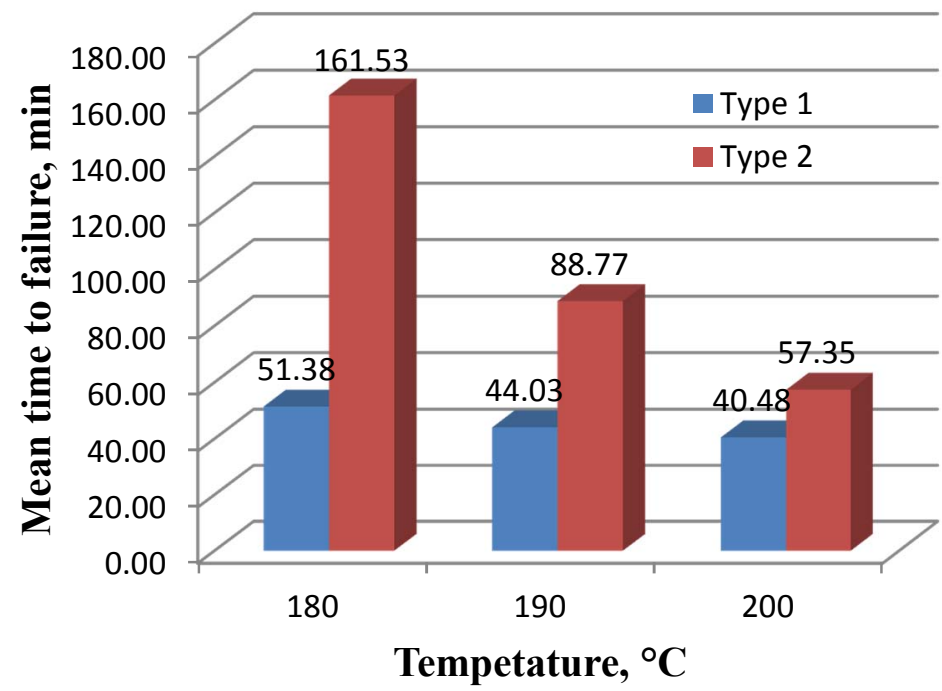

Fig. 4: Experimental results of corona resistance tests: study of temperature impact

Types of winding wires represented on Fig.4 are:

- Type 1 - doubly coated corona resistant enameled wire :

1 layer (inner) - 3-hydroxiethylcyanurate varnish, comprising silicon nanoparticles,

2 layer (outer) - polyamide imide varnish, 
- Type 2 - doubly coated enameled wire :

1 layer (inner) - polyester varnish,

2 layer (outer) - polyamide imide varnish.

One of the conducted experiments was study of insulation defectiveness on its endurance and effect of healing of through defects by impregnation. For this research the nondefective unimpregnated samples and samples having artificially made defects in their insulation, unimpregnated and impregnated by different varnishes, were tested. Artificial defects were in form of a ring defect (ring cutting of enamel insulation until reaching a core), one defect was made on one turn, and another defect on adjacent turn at distance between the defects equal to $0.10 \mathrm{~mm}$.

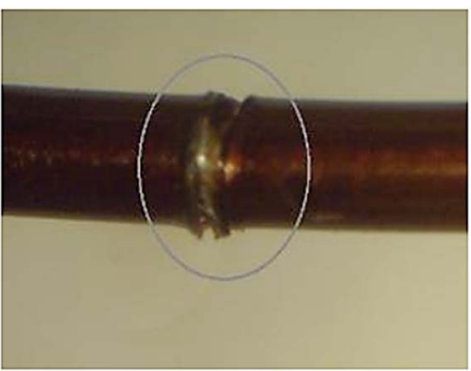

Fig. 5: View of a ring defect on the enameled wire

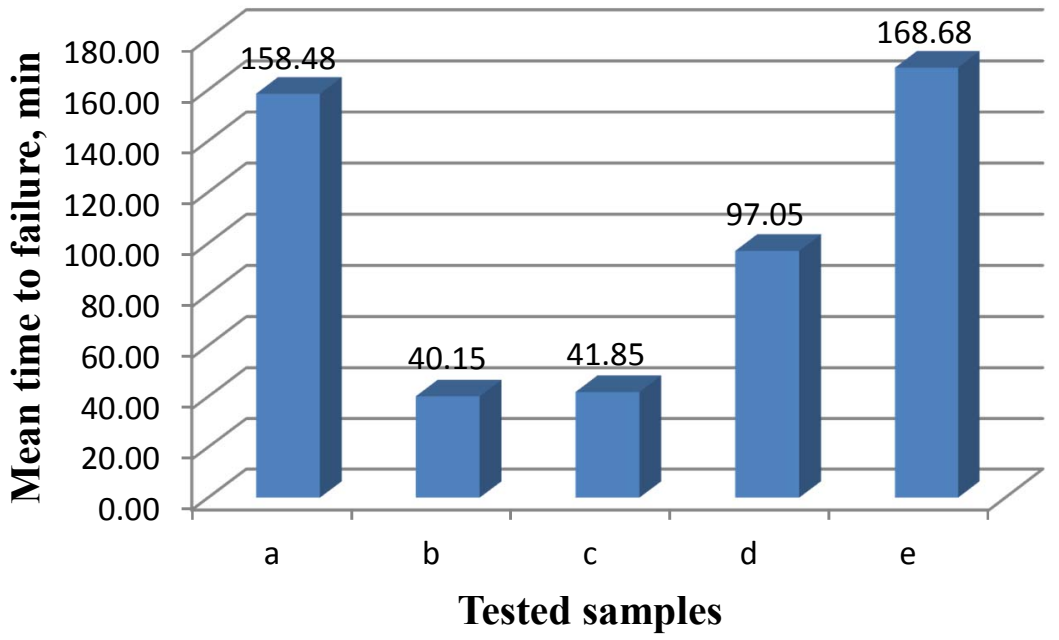

Fig. 6: study of defectiveness and effect of defects "healing" by impregnation

Tested samples shown on Fig. 6 are:

- $\quad \mathrm{a}$ - nondefective unimpregnated samples;

- $\mathrm{b}$ - unimpregnated defective samples; defective samples impregnated by:

- c - corona resistant organic-silicone varnish,

- $\mathrm{d}$ - polyether compound modified by organic-silicone resins,

- e-compound based on oligo-etheracrylates.

Using this bench, a numerous tests conducted in order to evaluate different types of winding wire insulation: conventional, corona-resistant and high thermal resistance wires, as well as different systems "enamel copper wire - impregnating varnish", non-defective samples and samples with artificial defects on turns, under separate and combined impact of thermal and electrical stresses (using design of experiments method). A large number of tests is required for obtain sufficient experimental data for rigor statistical analysis because insulation failures depends on many factors and random variables. Determination of mean time to failure doesn't permit to make a prognosis of wires service 
life during electrical machine's operation but to evaluate their quality, ability to withstand to operational stresses, and compatibility in the system "enamel wire - impregnating varnish" as an indicator of durability [7].

\section{High dV/dt testing method}

The experimental bench described in the previous paragraph allows the adequate reproducing of stresses typical for VFD with components based on silicon technology. Recent advances in power semiconductor engineering make it possible to create VFD that enable more quickly, accurately, and efficiently control of the electric machines due to availability of very powerful converters using high speed switches based on $\mathrm{SiC}$ and $\mathrm{GaN}$ technologies. The future large implementation of these semiconductors will revolutionize power electronics by allowing high temperature, very high switching frequency, and very high-voltage operation. Their higher-temperature performance will permit operation in much harsher environments; higher switching frequencies will lead to substantial reduction of size and weight, hence, contributing to lower cost and higher portability [22]. All listed outstanding features are especially important for transport and aeronautic applications. In order to carry out test and comparative analysis of electrical stresses changing due to implementation of $\mathrm{SiC}$ based high speed switches another test bench is designed (Fig.7).

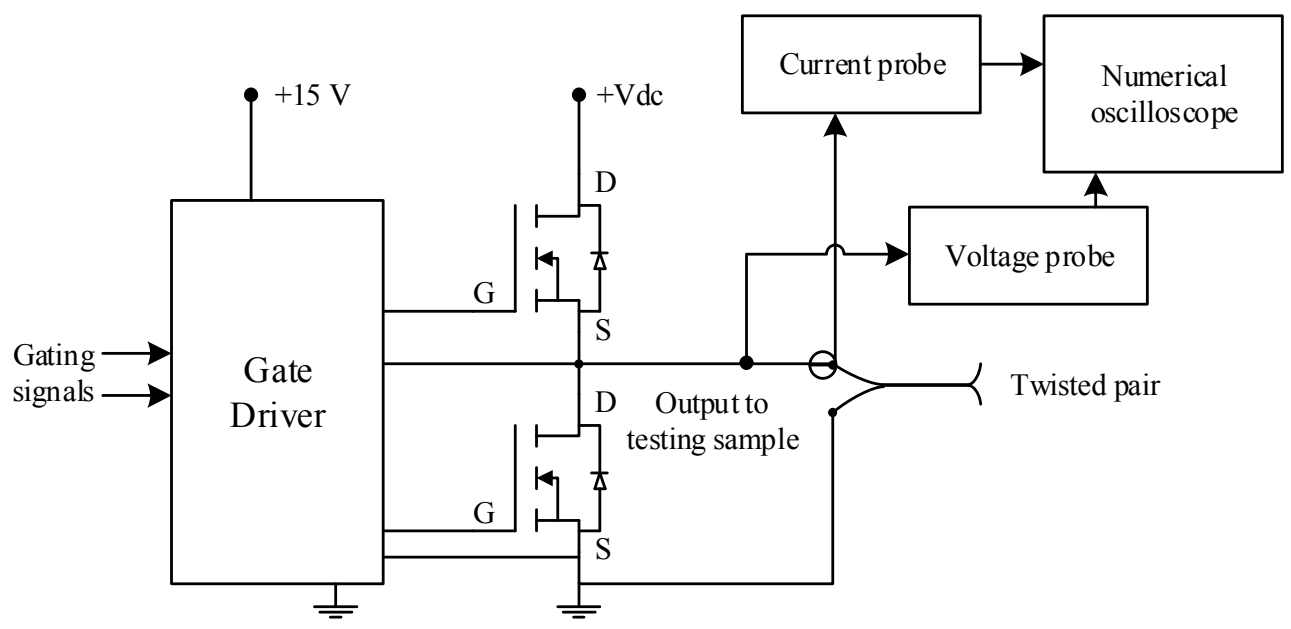

Fig. 7: Scheme of high $\mathrm{dV} / \mathrm{dt}$ test bench: half-bridge inverter

This scheme represents a pulse generator based on SiC MOSFET switches $\left(\mathrm{V}_{\mathrm{DS}}=1200 \mathrm{~V}, \mathrm{R}_{\mathrm{DS}(\mathrm{ON})}=\right.$ $280 \mathrm{~m} \Omega$ at $25^{\circ} \mathrm{C}$, Ref. Cree ${ }^{\circledR} \mathrm{C} 2 \mathrm{M} 0280120 \mathrm{D}$ [23]) which are controlled by the driver for industrial applications (Ref. Cree ${ }^{\circledR}$ CGD15HB62P1 [23]). A low output capacitance transistor (and thus the high on-state resistance) has been selected to maximize $\mathrm{dV} / \mathrm{dt}$ at the output of the inverter. The test circuit also incorporates the devices for measuring the voltage and the current at the input of the tested sample. To measure the voltage the Tektronix P3010 probe with a bandwidth of $100 \mathrm{MHz}$ is used. The power electronic components used in this test bench allow the application of voltage pulses with the maximum amplitude up to $1200 \mathrm{~V}$ and the switching frequency up to $64 \mathrm{kHz}$ (limitation of the driver). The voltage front $\mathrm{dV}_{\mathrm{DS}} / \mathrm{dt}$ is adjusted and controlled by modifying the gate resistance. This experimental set-up was designed in such a way as to minimize parasitic inductances and to form very high $\mathrm{dV} / \mathrm{dt}$. As in the test bench described in the preceding paragraph, one wire of the tested twisted pair is connected to the ground and to the other wire the voltage waves generated by the half-bridge inverter are applied. The wires' ends are in the air.

Figure 8 represents the measured voltage waveforms at the twisted pair terminals and current in the pair (of capacitive origin) during turn-on and turn-off switching at $150 \mathrm{~V}, 300 \mathrm{~V}$ and $400 \mathrm{~V}$. Values of $\mathrm{dV} / \mathrm{dt}$ were estimated: $50 \mathrm{kV} / \mu \mathrm{s}$ at $150 \mathrm{~V}$ and approximately $80 \mathrm{kV} / \mu \mathrm{s}$ at $400 \mathrm{~V}$. 
Switching on@150 V

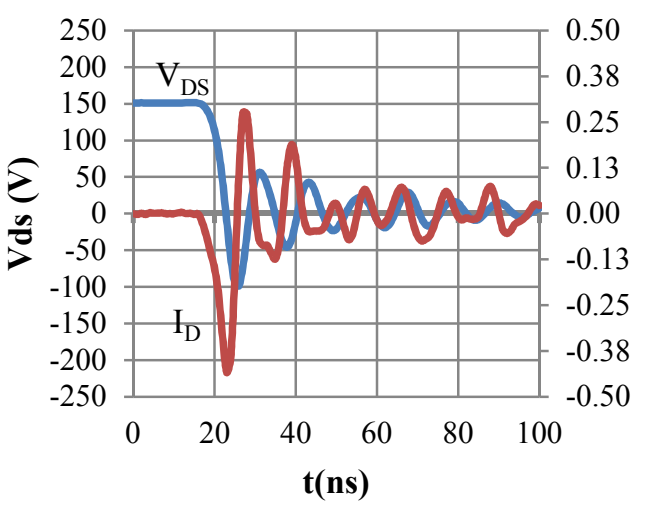

Switching on@300 V

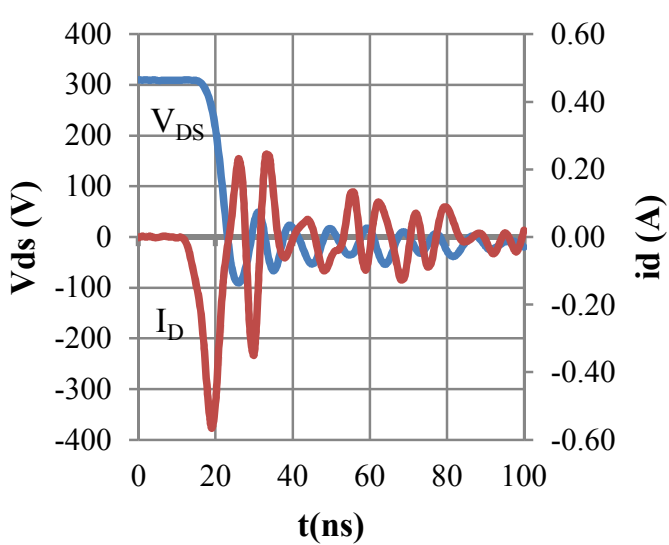

Switching on@400 V

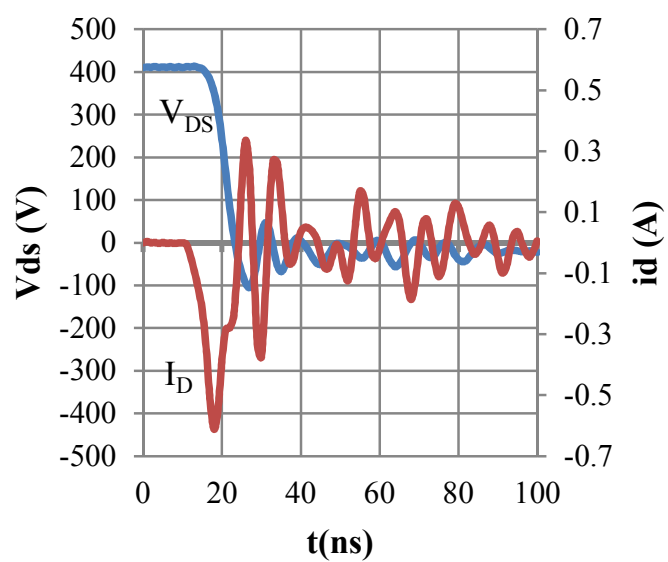

Switching off @150 V

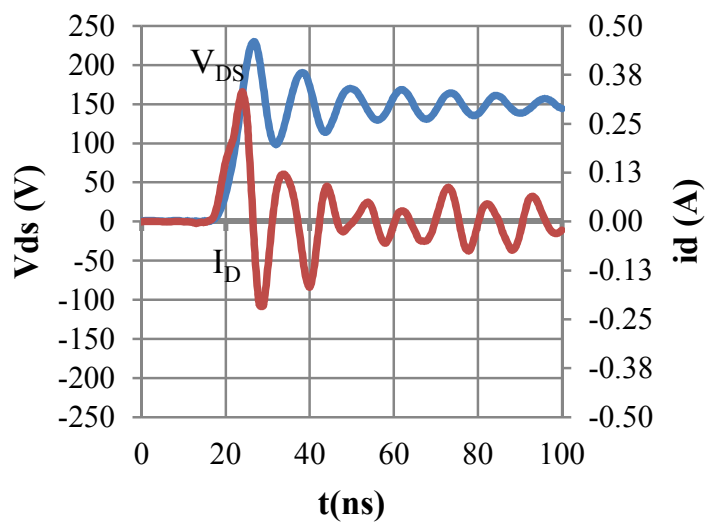

Switching off @ 300 V

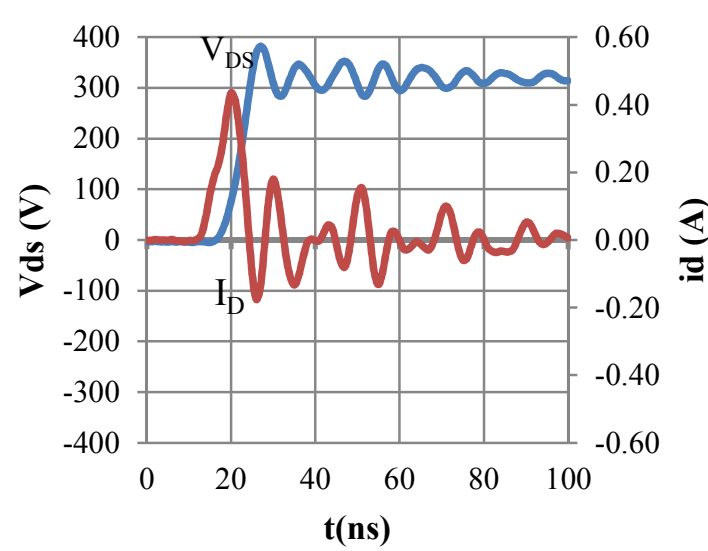

Switching off @400 V

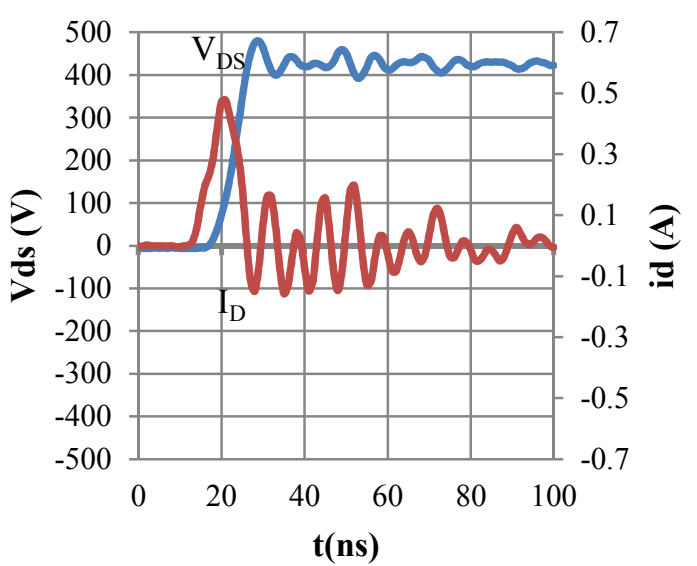

Fig. 8: Experimental results: waveforms of current and voltage applied to the twisted pair samples

This test bench already allows us to apply very steep voltage fronts, which can lower the PDIV. Whereas the previous studies [18] show that bipolar pulses can have a greater effect on insulation lifetime than unipolar pulses, so another pulse generator assembly was designed to evaluate this effect (Fig. 9). 


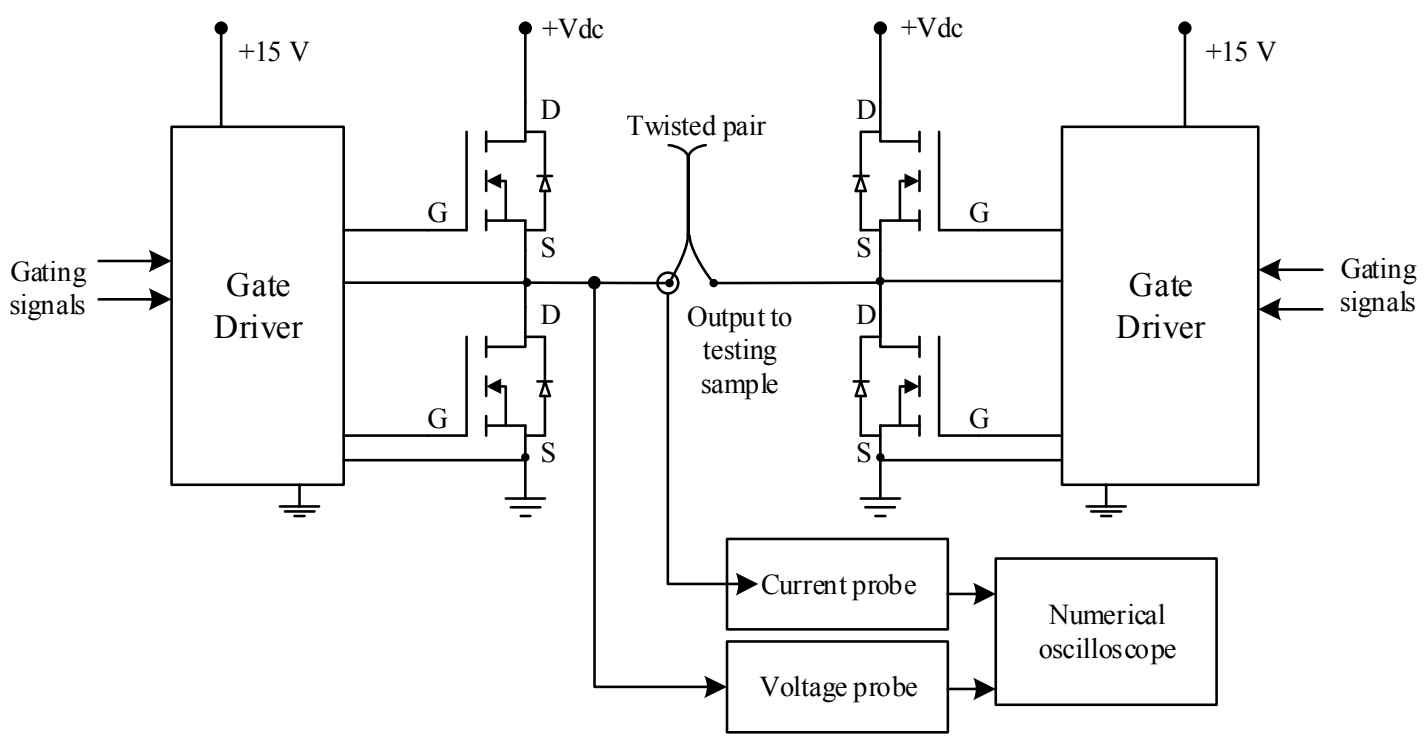

Fig. 9: Scheme of high $\mathrm{dV} / \mathrm{dt}$ test bench: single phase inverter

In this test bench, which is intended to work at higher voltage levels, other switches have been chosen (MOSFET SiC: $\mathrm{V}_{\mathrm{DS}}=1700 \mathrm{~V}, \mathrm{R}_{\mathrm{DS}(\mathrm{ON})}=1 \Omega$ at $25^{\circ} \mathrm{C}$, Cree ${ }^{\circledR}$ Ref. C2M1000170D [23]). They are also controlled by commercial drivers (Ref Cree ${ }^{\circledR}$ PT62SCMD17 [23]). These electronic power devices allow switching at maximal voltage up to $1700 \mathrm{~V}$. The drivers enable to set the dead time from 250 to $1000 \mathrm{~ns}$ and support $\mathrm{dV} / \mathrm{dt} \max$ up to $100 \mathrm{kV} / \mu \mathrm{s}$. This developed test bench is aimed to test twisted pairs and motorettes of winding wires for reproduce and investigate the influence of adjustable parameters such as $\mathrm{dV} / \mathrm{dt}$, voltage amplitude, or the length of the connecting cable, on the partial discharges appearance, on the lifetime of the wires estimated by the mean time to failure, and the aging process of the insulating material. It must be pointed out that to reproduce the thermo-aging process tested samples may be exposed to high temperature or be subjected to high pulse voltage after thermal aging. Furthermore, in order to obtain experimental results required to conduct a partial discharges analysis, to investigate the processes of insulation degradation, and to develop insulation lifetime models, the appropriate types and levels of applied stresses must be chosen as well as extensive studies are still regarded as necessary.

\section{Conclusion}

The development of wide bandgap power semiconductor technologies requires a change in approach and improvement of evaluating methods in accordance to the current state of the art. In this regard, it is crucial to design the experimental equipment enable to reproduce severe constraints imposed by high $\mathrm{dV} / \mathrm{dt}$ and high temperature in order to evaluate the electrical insulation materials withstand capability. To achieve this objective, a test bench allowing to generate pulses with very high $\mathrm{dV} / \mathrm{dt}$ wave fronts was developed. The possibility of controlling the $\mathrm{dV} / \mathrm{dt}$ by the gate resistance of the $\mathrm{SiC}$ MOSFETs used in the developed test benches provides the opportunity to study simultaneously the influence of voltage and $\mathrm{dV} / \mathrm{dt}$ on the wire's insulation, to analyze partial discharge appearance and dielectrics degradation mechanism.

Depending on the field of electric motors application, the test bench can be modified and influence of the other stresses can be studied, for example, the effect of the pressure for aeronautical applications, because according to Paschen's law the PDIV decreases with increasing pressure. The humidity has a less severe effect than pressure or temperature, but its influence in interaction with the mentioned factors can be investigated to complete the degradation analysis of insulation. In this case, the proposed test bench designed to reproduce the electrical stresses imposed by modern converters can be 
supplemented by a climate chamber making it possible to carry out tests in a controlled environment under the influence of a single influencing factor or combined with others.

\section{References}

[1] S. Grubic, J.M. Aller, B. Lu, T.G. Habetler, A survey on testing and monitoring methods for stator insulation systems of low voltage induction machines focusing on turn insulation problems. IEEE Transactions on Industrial Electronics, vol. 55, no. 12, 2008, pp. 4127-4136.

[2] M. Fenger, S.R. Campbell, J. Pedersen, Motor winding problems caused by inverter drives. IEEE Industry Applications Magazine, vol. 9, no. 4, 2003, pp. 22-31.

[3] J. A. Pomilio, C. R. de Souza, L. Matias, P. L. D. Peres, I. S. Bonatti, Driving AC motors through a long cable: the inverter switching strategy. IEEE Xplore Conference: Power Engineering Society General Meeting, Vol.14, 2007, pp. 1441 - 1447.

[4] N. Boucenna, S. Hlioui, B. Revol, F. Costa "A detailed analysis of the propagation paths of high-frequency currents in AC motors," Power Electronics and Applications (EPE), 2013 15th European Conference, pp. 1-6, 2013.

[5] O.V.Thorsen, M. Dalva, Interaction of System Parameters on AC Motor Transients in PWM Inverter Drives. IEEE Xplore Conference: Electric Machines and Drives Conference, 2001. IEMDC 2001. IEEE International, pp. $300-303$.

[6] Mihaila, Vasile. Nouvelle Conception des bobinages statoriques des machines à courant alternatif pour réduire les effets négatifs des dV/dt. Diss. Artois, 2011.

[7] A. Leonov, A. Supueva, V. Bolgova. Influence of Defects in Windings Insulation on its Operation Reliability. 2016 IEEE 16th International Conference on Environment and Electrical Engineering (EEEIC) 7-10 June 2016, Florence, Italy. Conference Proceedings, pp.742-745.

[8] F. Koliatene, T. Lebey, J. P. Cambronne, S. Dinculescu, "Impact of the aeronautic environment on the Partial Discharges Ignition: A basic study", Conference Record of the 2008 IEEE International Symposium on Electrical Insulation, ISEI 2008, 2008.

[9] Bartenev G.M. Prochnost' i mehanizm razrushenija polimerov. - M.: Himija, 1984. - $280 \mathrm{~s}$.

[10] Rotating electrical machines - Part 18-41: Partial discharge free electrical insulation systems (Type I) used in rotating electrical machines fed from voltage converters - Qualification and quality control tests.

[11] Rotating electrical machines - Part 18-42: Qualification and acceptance tests for partial discharge resistant electrical insulation systems (Type II) used in rotating electrical machines fed from voltage converters.

[12] Okubo, Hitoshi, Naoki Hayakawa, and Gian Carlo Montanari. "Technical development on partial discharge measurement and electrical insulation techniques for low voltage motors driven by voltage inverters." IEEE Transactions on Dielectrics and Electrical Insulation 14.6 (2007).

[13] Wang, Peng, Gian Carlo Montanari, and Andrea Cavallini. "Partial Discharge phenomenology and induced aging behavior in rotating machines controlled by power electronics." IEEE Transactions on Industrial Electronics 61.12 (2014): 7105-7112.

[14] P. Werynski, "Vieillissement des diélectriques et surveillance in situ des machines électriques", thèse, LSEE - Laboratoire Systèmes Electrotechniques et Environnement, Université d'Artois, Béthune, 2006.

[15] Guastavino, F., Cordano, D., Torello, E., \& Della Giovanna, L. (2016, October). PD evolution of conventional and corona resistant enamels. In Electrical Insulation and Dielectric Phenomena (CEIDP), 2016 IEEE Conference on (pp. 259-262). IEEE.

[16] Ray, Susanta, and Debangshu Dey. "Characterization of stator turn to turn faults of induction motor using cross-correlation analysis based features." Intelligent Control Power and Instrumentation (ICICPI), International Conference on. IEEE, 2016.

[17] Salameh, F., Picot, A., Chabert, M., \& Maussion, P. (2017). Parametric and non-parametric models for lifespan modeling of insulation systems in electrical machines. IEEE Transactions on Industry Applications.

[18] Narayanasamy, B., Sathyanarayanan, A. S., Deshpande, A., \& Luo, F. (2016, November). Analysis and mitigation of reflected wave voltages and currents in WBG devices based motor drives. In Wide Bandgap Power Devices and Applications (WiPDA), 2016 IEEE 4th Workshop on (pp. 297-301). IEEE.

[19] Barater, D., Immovilli, F., Soldati, A., Buticchi, G., Franceschini, G., Gerada, C., \& Galea, M. (2017). Multistress characterization of fault mechanisms in aerospace electric actuators. IEEE Transactions on Industry Applications, 53(2), 1106-1115. 
[20] Pulse width modulation simulator for testing insulating materials. US Patent No. 6051980, Is-sued on April 18,2000

[21] Determination of enamel insulation corona resistance by high-frequency modulated pulses / A. P. Leonov et al. // IOP Conference Series: Materials Science and Engineering. - 2015. - Vol. 81 : Radiation-Thermal Effects and Processes in Inorganic Materials. - [012094, 7 p.]

[22] A. Elasser and T. P. Chow, "Silicon carbide benefits and advantages for power electronics circuits and systems," Proc. IEEE, vol. 90, pp. 969-986, June 2002.

[23] http://www.wolfspeed.com/power/products. 